\title{
Application of the Improved Force Field Analysis on Airport Capacity Expansion Example
}

\author{
Milan KANKARAŠ, Nenad KAPOR, Ivana CVETKOVIĆ, Dalibor PETROVIĆ
}

\begin{abstract}
In this paper the process of force field analysis (hereafter: FFA) is analyzed, disadvantages of this method are noted and a mode is proposed which allows reducing those disadvantages and increasing the reliability of solving complex problems using the FFA. To improve FFA, a research is conducted, several different methods are applied, and more than 40 specialists are tested. A new model of FFA is offered which is improved by a decision making trial evaluation laboratory (hereafter: DEMATEL) method. Improvement of FFA by using DEMATEL method is explained in the case study that describes the determination by business success of air transport and airport various economic factors. The effect of those factors can be positive or negative. Based on the results of research in the case study it is concluded that the proposed model maintains all advantages of current model and reduces the disadvantages. Also, the improved method increases the reliability of FFA. In addition to the scientific contribution there is also a significant social contribution of this research, which is reflected in the application of the proposed model in decision-making process.
\end{abstract}

Keywords: Chi-square; DEMATEL; Driver Forces/Factors; Force Field Analysis; Process; Restraining Forces/Factors

\section{INTRODUCTION}

In the conditions of rapid and complex changes in the environment it is obligation of modern organizations to keep track of those changes and permanently make decisions in order to adapt the organization to future changes in the environment. In that process, the organization's management considers factors with more important influence on resolving the problem (decision) and examines their impact to determine the factors that have positive or negative influence on the problem.

In the literature several different methods are known that are used to support the decision-making process. One of these methods is FFA process. However, despite the advantages that FFA provides, there are imperfections in the application of this method as a consequence of unreliable results after applying FFA.

Therefore, a research is organized with the main goal of increasing the reliability of the results of FFA. The research is conducted in four phases: analysis of FFA process, production of the new FFA model, testing of the proposed FFA model on the case study of airport activities and evaluation of the proposed FFA process.

In the first phase current FFA process is separated into elements (phases of the process) by the method of analysis and a relationship is noticed among these elements (phases of the process). Furthermore, up lying the method of synthesis, all the elements of the process as well as their mutual relationships are perceived as a unity and basic advantages and disadvantages of FFA are identified. To confirm them opinions of specialists (persons with three or more years of experience in the application of FFA) are collected using data collected by surveying and processed by statistical method.

Taking into consideration aforementioned some changes in the process are proposed to reduce the identified disadvantages and to increase or at least maintain the perceived advantages of the achieved level. The proposed model is based on the use of DEMATEL method.

Testing the proposed model was implemented in the third phase of research on the case study of expansion of airports capacity in the Republic of Serbia. Proposed model is applied by ten experts to solve the problem of the expansion of airports capacity allowing complete overview of the functionality of the proposed FFA model.

In the last phase of research, scaling is applied to evaluate the proposed model and compare that estimate with the estimate of the initial-current model of FFA. Evaluation of the research results is carried out by the specialists, and the collected data are analyzed by statistical method.

\section{FORCE FIELD ANALYSIS - PROCESS, ADVANTAGES AND DISADVANTAGES}

Force field analysis was developed in the 1940s by Kurt Lewin, a German social psychologist [1]. The primary purpose of FFA is a systematic analysis of the factors found in complex problems. Every problem is unique, and there are different approaches to solving it. Whatever the approach, there is something that is common to solving all problems-factors that support the status quo and factors that support changes in the desired direction.

Many factors have an effect on solving different complex problems. Those factors are people, resources, attitudes, traditions, regulations, values, needs, desires, etc. An appropriate tool to solve problems or manage changes is FFA. It helps to identify factors that must be addressed and monitored if change is to be successful.

There are several different approaches to the process of FFA. Depending on author, FFA enables different number of steps. According to Kumar the process enables six steps [2]:

- write or draw the problem,

- identify driving and restraining forces,

- assign weights to each of the forces,

- discuss driving and restraining forces (which of the driving forces can be reinforced and which restraining forces can be diminished),

- intervene to forces (increase or reduce forces magnitude),

- make decision.

Regardless of the differences, FFA includes identifying driving and restraining forces, assigning score to the forces and comparison of total value of driving and restraining forces. Bearing in mind that every problem 
includes factors for troubleshooting and factors to try maintaining status quo, it is necessary to identify all factors affecting a problem situation. That is the first phase of FFA.

Identifying driving and restraining forces is usually realised by group working (up to 20 participants). The participants should recognize as many forces as possible [1]. The forces should be shown separately, driving forces in one group and restraining forces in the other.

The force impact on the problem situation is different. Some of the forces affect stronger, but some of them affect less. In the next stage, it is necessary to assign weights for each force according to their perceived impact on the problem [2]. About that, participants give each force a score of between 1 and 5 , where 1 is weak or low and 5 is strong or high [3]. Total driving/restraining forces score presents the sum of each driving/restraining force and allows their comparison.

There are three possible outcomes: the total driving forces score is higher than the total restraining forces score, the total driving forces score is lower than the total restraining forces score, and the total driving forces score and the total restraining forces score are equal. Sometimes, the result can be unexpected, and there may be a number of reasons (missing forces, inadequate forces, unrealistic forces score and so on). In that case, decision makers can correct forces or forces score over forces weight [1] and compare driving and restraining forces score again. At the end decision makers should recognize activities to increase the driving forces and activities to decrease the restraining forces. In this process brainstorming technique is very useful [2]. 1).

Process of FFA might be displayed graphically (Fig.

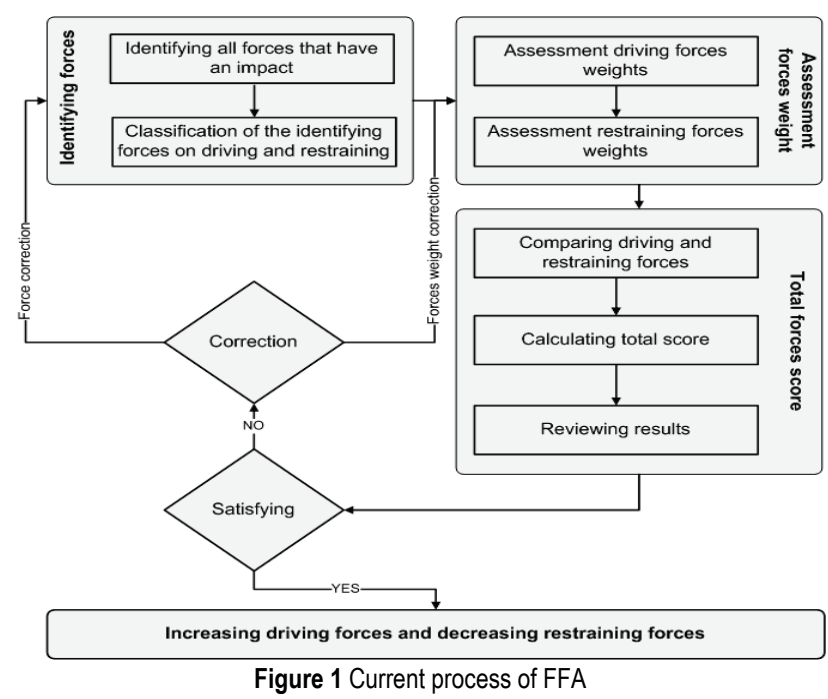

Application of FFA can be very useful in a decision making process. For example, some of advantages are simple use and good visualization of all forces (factors). Also, FFA enables easier identification of activities to be undertaken in order to eliminate or reduce the impact of restraining forces and making plans.

However, there are certain disadvantages. Firstly, the identified forces are not completely reliable. Experts have strong influence on selection of the forces. Also, some identified forces might not be relevant for solving the problem. Secondly, force weights are assessed subjectively without applying certain method. The assessment of weights has a significant impact on process outcome, and experts' judgment is decisive for FFA process result. Finally, if decision makers are not satisfied with the result, they affect the identified forces or their weights and change them.

There is a basic question of whether the process is used to support the decision-making process or to justify the decisions taken.

Bearing in mind identified advantages and disadvantages research is conducted with the aim of their ratification. The study includes employees in planning departments of public and commercial sector. In order to collect data and to validate identified advantages and disadvantages a questionnaire is made, and it is filled by 48 experts. The examinees answer the questions in the questionnaire with YES or NO. Also, it is possible to suggest extra advantages or disadvantages. The identified advantages and disadvantages are acceptable if there are significant differences between experts' answers and expected answers. Significant differences are tested by chisquare test $\left(\chi^{2}\right.$ test). In order to test significance differences, it is necessary to determine degrees of freedom, significance level and empirical value of $\chi^{2}$ test. Degrees of freedom are determined by Eq. (1).

$\mathrm{d} f=R-1$

where $\mathrm{d} f$ is degrees of freedom and $R$ is the number of levels for categorical variable. The empirical value of $\chi^{2}$ test is determined by Eq. (2) [4].

$\chi^{2}=\sum \frac{\left(O_{i}-E_{i}\right)^{2}}{E_{i}}$

where $O_{i}$ is the observed frequencies count (experts' answers) and $E_{i}$ is the expected frequencies count. Expected frequencies are calculated by Eq. (3) [4].

$E=n \cdot p$

where $n$ is the sample size and $p$ is the probability that element belongs to a category. In this case one degree of freedom and, as it is habitual [5-6], significance level is 0.05 , and there is one degree of freedom. Probability that element belongs to a category $(p)$ represents a normal distribution (0.5). Considering the degree of freedom and significance level, a null hypothesis is acceptable if empirical value of $\chi^{2}$ test is equal or less than 3.841 . Otherwise, an alternative hypothesis is acceptable.

Null and alternative hypotheses for significant differences between experts' answers and expected answers are stated as:

- $H_{o}$ : there is a not significant difference between experts' answers and expected answers,

- $H_{a}$ : there is a significant difference between experts' answers and expected answers.

Based on the analysis of FFA process four advantages are proposed: FFA is simple to use, FFA enables good 
visualization of all forces/factors, FFA enables easier identification of activities to be undertaken in order to eliminate or reduce the impact of restraining forces and making plans, and FFA enables to make plans. Answers of the examinees are shown in Tab. 1.

Table 1 Answers of the examinees about advantages of FFA process

\begin{tabular}{|l|c|c|}
\hline \multicolumn{1}{|c|}{ Advantages } & $\begin{array}{c}\text { Number of } \\
\text { answer YES }\end{array}$ & $\begin{array}{c}\text { Number of } \\
\text { answer NO }\end{array}$ \\
\hline FFA process is simple to use & 41 & 7 \\
\hline $\begin{array}{l}\text { FFA process enables good visualization } \\
\text { all forces/factors }\end{array}$ & 41 & 7 \\
\hline $\begin{array}{l}\text { FFA process enables easier identification } \\
\text { of activities to be undertaken in order to } \\
\text { eliminate or reduce the impact of } \\
\text { restraining forces and making plans }\end{array}$ & 41 & 7 \\
\hline FFA process enables to make plans & 41 & 7 \\
\hline
\end{tabular}

As is seen, experts are not suggesting extra advantages. By applying Eq. (2), the empirical value of $\chi^{2}$ test for each proposed advantage is 24.083 ( $>3.841)$, so there is a significant difference between experts' and expected answers, and alternative hypothesis is acceptable, respectively proposed advantages are acceptable.

Disadvantages of FFA are verified by the examinees in the same way as the advantages. The following disadvantages are proposed: identified forces are not completely reliable, assessment forces weight is subjective and force score is unreliable. Answers of the examinees are shown in Tab. 2.

Experts have not suggested extra disadvantages, and according to their answers, the determined empirical values of $\chi^{2}$ test are the following:

- Identified forces are not completely reliable 30.083 $(>3.841)$,

- Assessment forces weight is subjective 27.000 $(>3.841)$,

- $\quad$ Force score is unreliable $21.333(>3.841)$.

Table 2 Answers of the examinees about disadvantages of FFA process

\begin{tabular}{|l|c|c|}
\hline \multicolumn{1}{|c|}{ Disadvantages } & $\begin{array}{c}\text { Number of } \\
\text { answer YES }\end{array}$ & $\begin{array}{c}\text { Number of } \\
\text { answer NO }\end{array}$ \\
\hline $\begin{array}{l}\text { Identified forces are not completely } \\
\text { reliable }\end{array}$ & 43 & 5 \\
\hline Assessment forces weight is subjective & 42 & 6 \\
\hline Force score is unreliable & 40 & 8 \\
\hline
\end{tabular}

Taking into consideration aforementioned, every empirical value of $\chi^{2}$ test is more than reference value 3.841 , so there is a significant difference between experts' and expected answers, and alternative hypothesis is acceptable-proposed disadvantages are acceptable. Based on the opinions of examinees it is concluded that proposed advantages and disadvantages of FFA process are the characteristics which should improve or maintain the achieved level.

Focus of FFA upgrading should be improving identified disadvantages. Also, it ought not to ignore advantages, as well as it needs to improve them or maintain the achieved level.

\section{PROPOSED PROCESS OF FORCE FIELD ANALYSIS}

Improvement of FFA is based on the results of analysis of the process, and it is aimed at reducing subjectivity and increasing objectivity in FFA, as well as increasing reliability of FFA process results. The current procedure involves identifying all forces effect on solving problems and their classification, and at the end of FFA process it is possible to change identified forces. However, among the identified forces there are probably forces that have no effect on solving problem or their impact is negligible.

In that sense, after identifying all forces and their classification on the driving and restraining forces, and before assessment of forces weight, it is needed to determine the most significant (key) forces (driving and restraining), and reject other. Those forces can be determined by their cause and effect relationships. Some of identified forces affect the others and they are "cause forces". Some forces do not affect the others and they are "effect forces". In this connection effect forces are insignificant so they can be rejected. So, in this contest, DEMATEL method can be useful to determine cause forces.

DEMATEL method was originally developed by the Science and Human Affairs Program of the Battelle Memorial Institute of Geneva between 1972 and 1979 [7]. The main purpose of the method is studying the complex and intertwined problematic group.

The first step in application of DEMATEL method is gathering experts' opinion and calculating the average matrix $[8,9,7,10]$. In this step, each expert is asked to assess the degree of direct influence between two forces based on pair-wise comparison. The degree is ranged from zero to four, where 0 - no influence, 1 - low influence, 2 medium influence, 3 - high influence, and 4 - very high influence [7]. Individual expert's opinion is corresponded by element of matrix. Based on the individual expert's judgment in this step is calculated average mutual influence assessment matrix of identified driving and restraining forces that presents average experts' opinion Eq. (4).

$\bar{f}_{i j}=\frac{1}{n} \sum_{r=1}^{n} f_{k r}$

where $\bar{f}_{i j}$ is average individual expert's opinion, $f_{k r}$ is individual expert's opinion, $i$ is row, $j$ is column, $k$ is observed expert, $r$ is observed force and $n$ is number of experts. According to these determined elements average mutual influence assessment matrix is formed by Eq. (5).

$\bar{F}=\left[\bar{f}_{i j}\right]$

where $\bar{F}$ represents average mutual influence assessment matrix. The result of the first step in this stage is experts' opinion average matrices identified driving and restraining forces. The experts consider forces separately and possibility to influence the final forces determination and their score is decreased.

The next step enables deriving the total relation between identified forces and it is calculated by the following Eq. (6). [10].

$F=\hat{F}(I-\hat{F})^{-1}$ 
where $F$ is matrix of total relation between identified forces, $\hat{F}$ is normalized matrix, and $I$ is identity matrix. Elements of normalized matrix are the ratio of each element's average mutual influence assessment matrix and maximum amount of rows and columns of that matrix - Eq. (7) [7].

$$
\hat{\boldsymbol{F}}=\frac{\bar{f}_{i j}}{\max \left(\max _{1 \leq i \leq n} \sum_{j=1}^{n} \bar{f}_{i j}, \max _{1 \leq i \leq n} \sum_{i=1}^{n} \bar{f}_{i j},\right)}
$$

Thus, sum of rows represents the direct impact of the current force to the other forces and sum of columns represents the direct impact that a current force receives from the other forces. In order to select key driving and restraining forces it should determine the level of significance-threshold value.

The value of elements matrix of total relation between identified forces less than the threshold value are less important elements, and other elements are more significant. The threshold value is calculated by Eq. (8). [11].

$$
\alpha=\frac{\sum_{i=1}^{n} \sum_{j=1}^{n}\left[\bar{f}_{i j}\right]}{N}
$$

where $\alpha$ is threshold value and $N$ is number of matrix elements. However, in relation to the level of significance, threshold can be performed as experts' agreement or a quartile. For example, if the level of significance is higher, threshold should perform as the third quartile or the first quartile if the level of significance is lower.

On the basis of threshold value, a force that has no effect to other forces is rejected-the row with elements less than threshold value (Tab. 3). As it is shown in Tab. 3 force $F-3$ is rejected because it has no effect to other forces, and just receives impact from the other.

\begin{tabular}{|c|c|c|c|}
\multicolumn{5}{|c}{ Table 3 Rejected forces } \\
\hline Force & $F-1$ & $F-2$ & $F-3$ \\
\hline$F-1$ & $>\alpha$ & $<\alpha$ & $>\alpha$ \\
\hline$F-2$ & $<\alpha$ & $>\alpha$ & $>\alpha$ \\
\hline$F-3$ & $<\alpha$ & $<\alpha$ & $<\alpha$ \\
\hline
\end{tabular}

This phase enables determination of key driving and restraining forces based on predefined criteria, and not on the basis of experts' consensus. Also, this stage is one of the main changes of FFA process. The results of this stage are the selected key driving and the key restraining forces.

Based on that, new matrices are formed-average mutual influence matrices of key driving and key restraining forces. Their elements are average mutual influence assessment matrix elements $\left(\bar{f}_{i j}\right)$ with no elements of rejected forces (Tab. 4.).

Table 4 Key driving or key restraining forces matrix
\begin{tabular}{|c|c|c|c|}
\hline Force & $F-1$ & $F-2$ & $F-3$ \\
\hline$F-1$ & $\bar{f}_{11}$ & $\bar{f}_{12}$ & $\bar{f}_{13}$ \\
\hline \multirow{2}{*}{$F-2$} & $\bar{f}_{21}$ & $\bar{f}_{22}$ & $\bar{f}_{23}$ \\
\hline
\end{tabular}

Beyond, total forces influence is performed simply through three steps: calculating key driving forces influence, key restraining forces influence and comparing those results. Key driving $\left(I_{\mathrm{df}}\right)$ or key restraining forces influence $\left(I_{\mathrm{rf}}\right)$ is sum of influence of each key driving or key restraining force Eq. (9).

$$
I_{\mathrm{df}}, I_{\mathrm{rf}}=\sum_{i=1}^{n} I_{\mathrm{r} i}
$$

where $I_{\mathrm{r} i}$ is influence of each key driving or key restraining force and it is calculated as sum of $i^{\text {th }}$ row in average mutual influence matrices of key driving and key restraining forces Eq. (10).

$$
I_{\mathrm{r} i}=\sum_{i=1}^{n} r_{i}
$$

The last step in this stage is calculating total forces influence $\left(I_{\mathrm{t}}\right)$ as the result of subtraction of key driving and key restraining forces influence Eq. (11).

$$
I_{\mathrm{t}}=I_{\mathrm{df}}-I_{\mathrm{rf}}
$$

Finally, it is useful to have opportunity to check the result of FFA. If the decision maker requires checking of results, planners should check the second and the third phase of FFA. Otherwise, planners should specify the actions to increase key driving forces and to decrease key restraining forces. Proposed FFA can be presented as algorithm (Fig. 2).

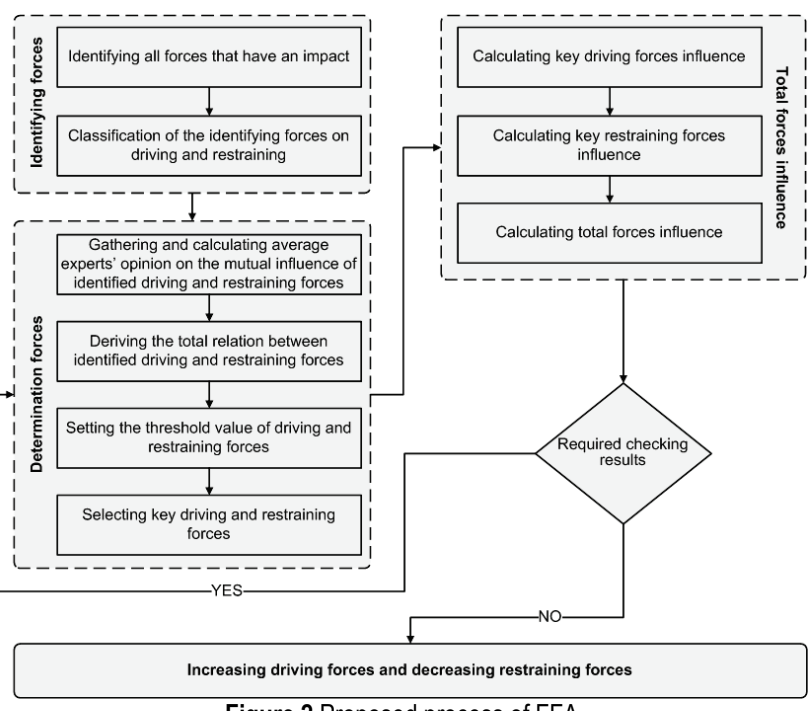

Figure 2 Proposed process of FFA

For the sake of checking of FFA it is necessary to test it in practice.

\section{TESTING PROPOSED PROCESS OF FORCE FIELD ANALYSIS}

Every researcher doubts the validity of their work, i.e. in this case the validity of FFA. In that sense, the research is conducted and proposed FFA process is tested. The FFA can be used in many different areas, but in this case the 
proposed FFA process is tested on air traffic in the Republic of Serbia.

According to data of Airport Nikola Tesla Belgrade since 2003 there has been a steady increase of air traffic in the Republic of Serbia [12]. The increase was checked by three indicators: aircraft movements, number of passengers, cargo and mail. The aircraft movements (number of take-offs and landing) are increased by $80 \%$ (Fig. 3).

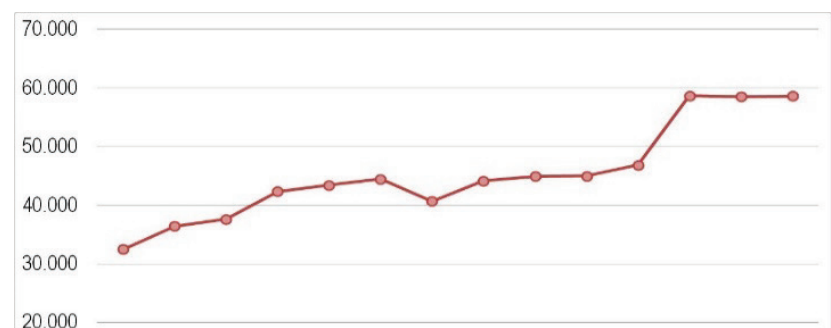

10.000

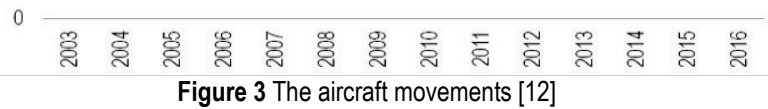

Similar to aircraft movements, since 2003 number of passengers and cargo are doubled (Fig. 4).

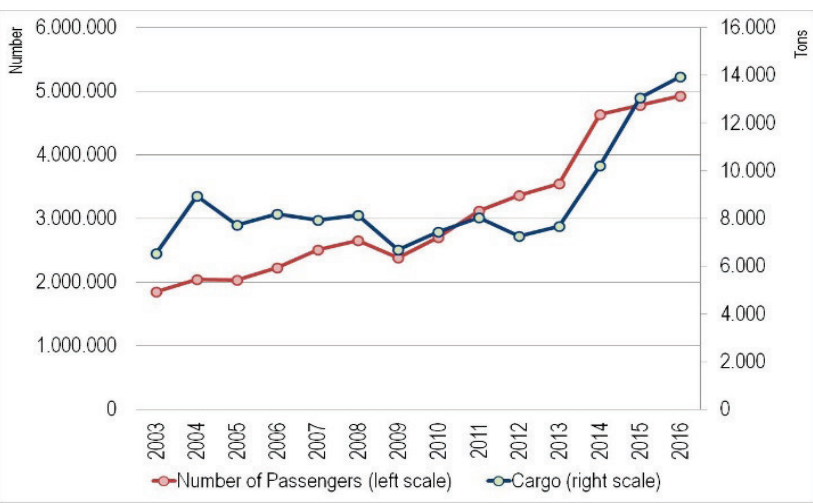

Figure 4 Number of passengers and cargo [12]

Bearing in mind significant increase of air traffic in the Republic of Serbia, competent authorities should think about expansion of airports capacity. The idea of expansion might be analyzed by the proposed FFA process.

The proposed FFA process is tested on the case study of the effect of economic factors on the expansion of airports capacity in the Republic of Serbia. To test the proposed FFA method an expert group of specialistseconomists and air traffic experts is found. Taking into consideration that all selected economists are not closely profiled to the increasing of airports capacity the formation of expert group is conducted using measures of closeness of expert's estimates to average value of estimate of group [13].

Taking into consideration the analysis of the literature [14-20], nine economic factors are selected, which are applied during the formation of experts group and testing of the proposed FFA method. Economic factors are: infrastructure capacity, resource capacity, credit ability, market needs, quality of personnel, quantity of personnel, credit financing, market competition and variable interest rate.
Following the procedure of the proposed FFA and based on the analysis of literature, selected experts were offered nine factors that affect the expansion of the airports capacity. The experts have classified the forces and the output of this stage is a list of driving forces (infrastructure capacity, resource capacity, credit ability, market needs, and quality of personnel) and a list of restraining forces (quantity of personnel, credit financing, market competition and variable interest rate).

In the next step, driving forces list is converted to driving forces matrix, and restraining forces list is converted to restraining forces matrix. Experts assess the degree of direct influence between two identified driving and restraining forces based on pair-wise comparison. According to the individual direct influence of driving and restraining forces matrices, mutual influence assessment matrix of identified driving forces is calculated by Eq. (4) and formed by Eq. (5) (Tab. 5).

Table 5 Mutual influence assessment matrix of identified driving forces

\begin{tabular}{|c|c|c|c|c|c|}
\hline $\begin{array}{c}\text { Driving } \\
\text { force }\end{array}$ & DF-1 & DF-2 & DF-3 & DF-4 & DF-5 \\
\hline DF-1 & 0.00 & 3.00 & 3.00 & 2.75 & 2.45 \\
\hline DF-2 & 2.80 & 0.00 & 3.10 & 2.70 & 1.90 \\
\hline DF-3 & 3.35 & 3.45 & 0.00 & 3.25 & 2.00 \\
\hline DF-4 & 3.05 & 2.50 & 3.25 & 0.00 & 2.65 \\
\hline DF-5 & 2.05 & 2.25 & 3.05 & 2.95 & 0.00 \\
\hline
\end{tabular}

Likewise, mutual influence assessment matrix of identified restraining forces is calculated by Eq. (4) and formed by Eq. (5) (Tab. 6).

Table 6 Mutual influence assessment matrix of identified restraining forces

\begin{tabular}{|c|c|c|c|c|}
\hline $\begin{array}{c}\text { Restraining } \\
\text { force }\end{array}$ & RF-1 & RF-2 & RF-3 & RF-4 \\
\hline RF-1 & 0.00 & 2.98 & 2.38 & 2.81 \\
\hline RF-2 & 3.17 & 0.00 & 3.17 & 2.33 \\
\hline RF-3 & 2.95 & 2.38 & 0.00 & 2.76 \\
\hline RF-4 & 3.45 & 2.86 & 3.45 & 0.00 \\
\hline
\end{tabular}

Applying Eq. (6) to Eq. (8) matrix of total relation between identified driving forces is calculated, as well as forces that have no effect on the other forces-rejected forces. Bearing in mind that threshold value is 1.77 , there is not one rejected force (Tab. 7).

Table 7 Matrix of total relation between identified driving forces

\begin{tabular}{|c|c|c|c|c|c|}
\hline $\begin{array}{c}\text { Driving } \\
\text { force }\end{array}$ & $D F-1$ & $D F-2$ & $D F-3$ & $D F-4$ & $D F-5$ \\
\hline$D F-1$ & 1.69 & 1.85 & 1.98 & 1.88 & 1.52 \\
\hline$D F-2$ & 1.80 & 1.57 & 1.90 & 1.80 & 1.42 \\
\hline$D F-3$ & 2.01 & 1.97 & 1.89 & 2.01 & 1.58 \\
\hline$D F-4$ & 1.92 & 1.85 & 2.02 & 1.73 & 1.56 \\
\hline$D F-5$ & 1.73 & 1.70 & 1.87 & 1.78 & 1.27 \\
\hline
\end{tabular}

Matrix of total relation between identified restraining forces and rejected ones is calculated in the same way as previous matrix. According to the threshold value 1.92 there is one rejected force $R F-1$. (Tab. 8).

Table 8 Matrix of total relation between identified restraining forces

\begin{tabular}{|c|c|c|c|c|}
\hline $\begin{array}{c}\text { Restraining } \\
\text { force }\end{array}$ & $R F-1$ & $R F-2$ & $R F-3$ & $R F-4$ \\
\hline$R F-1$ & 1.81 & 1.86 & 1.91 & 1.81 \\
\hline$R F-2$ & 2.12 & 1.69 & 2.02 & 1.84 \\
\hline$R F-3$ & 2.02 & 1.80 & 1.70 & 1.79 \\
\hline$R F-4$ & 2.32 & 2.08 & 2.21 & 1.81 \\
\hline
\end{tabular}


These matrices enable to calculate total forces influence. Key driving forces influence is calculated by Eq. (9) and Eq. (10) and that influence is 44.30 (Tab. 9).

Table 9 Key driving forces influence
\begin{tabular}{|c|c|c|c|c|c|c|}
\hline $\begin{array}{c}\text { Driving } \\
\text { force }\end{array}$ & $D F-1$ & $D F-2$ & $D F-3$ & $D F-4$ & $D F-5$ & $I_{\text {ri }}$ \\
\hline$D F-1$ & 1.69 & 1.85 & 1.98 & 1.88 & 1.52 & 8.92 \\
\hline$D F-2$ & 1.80 & 1.57 & 1.90 & 1.80 & 1.42 & 8.49 \\
\hline$D F-3$ & 2.01 & 1.97 & 1.89 & 2.01 & 1.58 & 9.46 \\
\hline$D F-4$ & 1.92 & 1.85 & 2.02 & 1.73 & 1.56 & 9.08 \\
\hline$D F-5$ & 1.73 & 1.70 & 1.87 & 1.78 & 1.27 & 8.35 \\
\hline \multicolumn{7}{|c|}{$I_{\text {df }}$} \\
\hline
\end{tabular}

Key restraining forces influence is 23.40 , and it is calculated in the same way as the previous (Tab. 10).

Table 10 Key restraining forces influence

\begin{tabular}{|c|c|c|c|c|c|}
\hline Restraining force & $R F-1$ & $R F-2$ & $R F-3$ & $R F-4$ & $I_{\mathrm{ri}}$ \\
\hline$R F-2$ & 2.12 & 1.69 & 2.02 & 1.84 & 7.67 \\
\hline$R F-3$ & 2.02 & 1.80 & 1.70 & 1.79 & 7.31 \\
\hline$R F-4$ & 2.32 & 2.08 & 2.21 & 1.81 & 8.42 \\
\hline \multicolumn{7}{|c|}{$I_{\mathrm{rf}}$} \\
\hline
\end{tabular}

According to the key driving and key restraining forces influence and Eq. (11), total forces influence is 20.90 respectively the key driving forces more increasingly affect the expansion of airports capacity than the key restraining forces.

As is shown, the proposed FFA works properly in practice, so it is necessary to check its betterment.

\section{IMPROVEMENT EVALUATION OF PROPOSED PROCESS OF FORCE FIELD ANALYSIS}

The improvement of the proposed FFA process is evaluated by 45 employees with three years or more experience in the application of FFA. The employees fill questionnaire and award current FFA process 1 to 5 points for each feature; mark 1 represents the smallest degree of feature and 5 the greatest degree of FFA process.

Bearing in mind the identified advantages and disadvantages, the following features are awarded by employees:

- Usability represents easiness of use of FFA process;

- Visualization means good understanding of all identified/determined forces;

- Identification of activities to be undertaken to eliminate or reduce the impact of restraining forces;

- Enabling the development of the plan is closely linked to the previous characteristic;

- Certain forces reliability represents trust in the identified/determined forces; and

- Forces score reliability is the confidence of the result of FFA.

Opinion of the employees for each feature of current FFA process is displayed in Tab. 11. Also, according to the opinions average mark for each feature is calculated by Eq. (12), and is shown in the table.

$M F_{i}=\frac{\sum_{i=1}^{n} V_{i} \cdot C_{i}}{m}$ where $M F_{i}$ is average feature mark, $V_{i}$ is value of point (1 to 5), $C_{i}$ is number of employees who are awarded certain value of point and $m$ is the total number of employees.

Table 11 Disposition of employee opinions of current FFA process

\begin{tabular}{|l|c|c|c|c|c|c|}
\hline \multicolumn{1}{|c|}{ Feature } & 1 & 2 & 3 & 4 & 5 & $\begin{array}{c}\text { Average } \\
\text { feature mark }\end{array}$ \\
\hline Usability & 1 & 1 & 5 & 30 & 8 & 3.96 \\
\hline Visualization & 1 & 1 & 6 & 31 & 6 & 3.89 \\
\hline $\begin{array}{l}\text { Enabling the development of } \\
\text { the plan }\end{array}$ & 1 & 3 & 21 & 14 & 6 & 3.47 \\
\hline Certain forces reliability & 9 & 14 & 15 & 6 & 1 & 2.47 \\
\hline Force score reliability & 10 & 16 & 12 & 6 & 1 & 2.38 \\
\hline \multicolumn{7}{|l|}{ Average mark of current FFA process } \\
\hline
\end{tabular}

After evaluation of the current FFA, the proposed model was explained and the employees had a month to try it. Later on, the employees have awarded the proposed FFA process, and the results are shown in Tab. 12.

As seen, in the tables there is average mark of FFA process. The average mark is calculated by Eq. (13).

$M P_{i}=\frac{\sum_{i=1}^{n} M F_{i}}{M}$

Table 12 Disposition of employee opinions of proposed FFA process

\begin{tabular}{|l|c|c|c|c|c|c|}
\hline \multicolumn{1}{|c|}{ Feature } & 1 & 2 & 3 & 4 & 5 & $\begin{array}{c}\text { Average } \\
\text { feature mark }\end{array}$ \\
\hline Usability & 1 & 1 & 7 & 25 & 11 & 3.98 \\
\hline Visualization & 1 & 1 & 4 & 32 & 7 & 3.96 \\
\hline $\begin{array}{l}\text { Enabling the } \\
\text { development of the } \\
\text { plan }\end{array}$ & 1 & 2 & 13 & 25 & 4 & 3.64 \\
\hline $\begin{array}{l}\text { Certain forces } \\
\text { reliability }\end{array}$ & 5 & 6 & 18 & 12 & 4 & 3.09 \\
\hline Force score reliability & 7 & 8 & 13 & 12 & 5 & 3.00 \\
\hline Average mark of proposed FFA process & & 3.53 \\
\hline
\end{tabular}

Where $M P_{i}$ is average mark of FFA and $M$ is the total number of features. The employees awarded differently the current and proposed FFA process, so it is necessary to test significance of these differences. The significance is tested in 4 following issues:

1) significance differences between each feature of FFA;

2) significance differences between average marks of FFA;

3) ratio of the average feature marks of proposed and current FFA, and

4) ratio of the average mark of proposed and current FFA process.

Significance differences between features and average marks are tested by a chi-square test. In both cases significance level is 0.05 , and there are 4 degrees of freedom Eq. (1). Likewise, the expected frequencies in both cases are the awarded frequencies of current FFA, and the observed frequencies are the awarded frequencies of proposed FFA. The empirical value of $\chi^{2}$ test is determined by Eq. (2). Considering the degrees of freedom (4) and significance level $(0.05)$, a null hypothesis is acceptable if empirical value of $\chi^{2}$ is equal or less than 9.488. Otherwise, an alternative hypothesis is acceptable.

Null and alternative hypotheses for significant differences between features and between average marks are stated as: 
- $H_{o}$ : there is a not significant difference between proposed and current FFA process, and

- $H_{a}$ : there is a significant difference between proposed and current FFA process.

In accordance with aforementioned, the empirical values of $\chi^{2}$ test for each feature are calculated by Eq. (2) and the results are shown in Tab. 13.

As it is seen from Tab. 13. cal values of $\chi^{2}$ test of Usability and Visualization are less than 9.488 , so there are not significance differences between proposed and current FFA process in that sense. However, the empirical values of $\chi^{2}$ test of Enabling the development plan, Certain forces reliability and Force score reliability are more than 9.488, so there is a significant difference between proposed and current FFA process in this respect.

\begin{tabular}{|c|c|}
\hline Feature & $\chi^{2}$ \\
\hline Usability & 2.758 \\
\hline Visualization & 0.866 \\
\hline Enabling the development of the plan & 12.690 \\
\hline Certain forces reliability & 21.494 \\
\hline Force score reliability & 26.983 \\
\hline
\end{tabular}

Also, based on empirical value of $\chi^{2}$ test of average marks of proposed and current FFA process $(0.330)$ it can be inferred that there is a not significant difference between the proposed and the current FFA process.

Ratio $\left(R_{i}\right)$ of the average feature marks of proposed and current FFA process and ratio of the average mark of proposed and current FFA process is calculated by Eq. (14).

$R_{i}=\frac{M F_{i}}{M F_{i}}$ or $\frac{M P_{i}}{M P_{i}}$

Based on Eq. (14) empirical ratio values are calculated and are displayed in Tab. 14.

Table 14 Empirical ratio values

\begin{tabular}{|l|c|}
\hline \multicolumn{1}{|c|}{ Average mark } & $R$ \\
\hline Usability & 1.01 \\
\hline Visualization & 1.02 \\
\hline Enabling the development of the plan & 1.05 \\
\hline Certain forces reliability & 1.25 \\
\hline Force score reliability & 1.26 \\
\hline FFA process & 1.09 \\
\hline
\end{tabular}

The proposed FFA process has been evaluated in 4 issues and the main results are as follows:

1) every advantage of current FFA is maintained on the same level or improved,

2) every disadvantage of current FFA is improved,

3) all features are evaluated the same or greater grade.

4) the proposed FFA is evaluated greater than current.

Taking into account the specified it can be inferred that the proposed FFA works properly and it is better than the current FFA.

\section{ACKNOWLEDGMENT}

The results presented in this paper are made within project No VA-DH/3/17-19 supported by the University of
Defence of Ministry of Defence of the Republic of Serbia.

\section{CONCLUSION}

In the paper are presented the results of research aimed at increasing the reliability of the results of FFA. Therefore, in order to determine the advantages and disadvantages of FFA, available literature is studied which relates to FFA process and its practical application. Also, FFA process is analyzed in detail.

Basic advantages and disadvantages of this method are determined by the analysis of FFA. Based on 48 experts four advantages are confirmed (FFA process is simple to use, FFA process enables good visualization of all forces/factors, FFA process enables easier identification of activities to be undertaken in order to eliminate or reduce the impact of restraining forces and making plans, and FFA process enables to make plans) and three basic disadvantages (identified forces are not completely reliable, assessment forces weight is subjective and force score is unreliable).

Application of the proposed model provides a more objective determination of driving and restraining forces enabling the calculation of their affects on the solution of complex problems. The proposed model is tested to solve hypothetical problems and during testing in its implementation problems are not observed.

At the end of the research it is carried out estimate of the proposed model and comparison with the current one in order to determine the level of reliability of the process. Estimate of the current and the proposed model process is carried out by 45 experts (after a period of one month of the beginning of the application of the proposed model). The processes are evaluated according to five basic characteristics: Usability, Visualization, Enabling the development of the plan, Certain forces reliability, and Force score reliability. Based on the opinion of the experts it is concluded that there is no indication that the current model is better than the proposed model.

The research results indicate that the proposed model allows improving the basic advantages or their maintenance at least at the same level, and that allows reduction of the main disadvantages. Also, the characteristics of the proposed model are evaluated approximately at the same or higher level, and the whole process is evaluated higher estimate than the current model.

Based on the aforementioned it can be concluded that the proposed model increases the reliability of the FFA process. Also, this research has manifold contributions and includes scientific and social sphere. In the scientific sphere the research has a positive effect on the expansion of theoretical knowledge in the field of management, decision theory and methodology, and in the social sphere contribution is reflected in the possibility of using this model in the decision-making process and in increasing objectivity in solving practical problems.

Based on the results which are presented in this paper it is possible to look at future directions of researches in this area. Namely, in further researches it is necessary to consider the need for prioritization driving and restraining forces, as well as the possibility to automate the process by creating adequate FFA software or software application. 


\section{REFERENCES}

[1] Hustedde, R. \& Score, M. (1995). Force-Field Analysis: Incorporating Critical Thinking in Goal Setting. CD Practice; 4, 2-7.

[2] Kumar, S. (1999). Force field analysis: applications in PRA. PLA Notes (36), 17-23.

[3] Mftrou. (n.d.). Retrieved August 2, 2016: from http://www.mftrou.com/.

[4] Mann, P. S. (2013). Introductory Statistics, eighth edition. Hoboken, NJ: John Wiley \& Sons, Inc.

[5] Kuhberger, A., Fritz, A., \& Schemdl, T. (2014). Publication bias in psychology. PLoS one.

[6] Gorard, S. \& Gorard, J. (2016). What to do instead of significance testing? Calculating the 'number of counterfactual cases needed to disturb a finding'. International Journal of Social Research Methodology, 19(4), 481-490. https://doi.org/10.1080/13645579.2015.1091235

[7] Sumrit, D. \& Anuntavoranich, P. (2013). Using DEMATEL Method to Analyze the Casual Relations on Technological Innovation Capability Evaluation Factors in Thai Technology-Based Firms. International Transaction Journal of Engineering, Management, \& Applied Sciences \& Technologies, 81-103.

[8] Yi Wu, H. (2012.). Constructing a strategy map for banking institutions with key performance indicators of the balanced scorecard. Evaluation and program planning, 35(3), 303320. https://doi.org/10.1016/j.evalprogplan.2011.11.009

[9] Wu, W.-W. \& Lee, Y.-T. (2007). Developing global managers' competencies using the fuzzy DEMATEL method. Expert Systems with Applications, 32(2), 499-507. https://doi.org/10.1016/j.eswa.2005.12.005

[10] Moghaddam, N. B., Sahafzadeh, M., Alavijeh, A. S., Yousefdehi, H., \& Hosseini, S. H. (2010). Strategic Environment Analysis Using DEMATEL Method Thorogh Systematic Approach: Case Study of an Energy Research Institute in Iran. Management Science and Engineering, 4(4), 95-105.

[11] Yang, Y., Shieh, H., Leu, J., \& Tzeng, G. (2008). A novel hybrid MCDM model combined with DEMATEL and ANP with applications. International Journal Operational Research, 5(3), 160-168.

[12] Airport Nikola Tesla Belgrade. (n.d.). Retrieved August 30, 2017, from Traffic Figures Archive: Airport Nikola Tesla Belgrade. (n.d.). Retrieved August 30, 2017, from TrafficFigures-Archive: http://www.beg.aero/en/strana/11191/Архива-статистике.

[13] Marcinkovskij, D. (2011). Ispoljzovanie metoda ekspertnih ocenok pri analize i ocenke riskov sistemi menedžmentsa. Itech - intellektualnie tehnologii: žurnal intellektualnih tehnologij, 18(4), 1-13.

[14] Begley, T. M., Tan, W. L., \& Schoch, H. (2005). Politicoeconomic factors associated with interest in starting a business: A multi-country study. Entrepreneurship Theory and Practice, 29(1), 35-55. https://doi.org/10.1111/j.1540-6520.2005.00068.x

[15] Chittithaworn, C., Islam, M. A., Keawchana, T., \& Yusuf, D. H. M. (2011). Factors affecting business success of small \& medium enterprises (SMEs) in Thailand. Asian Social Science, 7(5), 180-190. https://doi.org/10.5539/ass.v7n5p180

[16] Islam, M. A., Mian, E., \& Ali, M. H. (2008). Determinants of business success of Small and Medium Enterprises (SMEs) in Bangladesh. Business Review, 4(2), 45-57.

[17] Gadenne, D. (1998): Critical success factors for small business: an inter-industry comparison. International Small Business Journal, 17(1), 36-56. https://doi.org/10.1177/0266242698171002

[18] Ghosh, B. \& Kwan, W. (1996). An analysis of key success factors of SMEs: a comparative study of Singapore/Malaysia and Australia/New Zealand. In The $41^{\text {st }}$ ICSB World Conference Proceedings I (215-252). Sweden: Stockholm.

[19] Sebjan, U., Tominc, P., \& Sirec, K. (2017). Multiple conceptual modelling of perceived quality of in-flight airline services. Promet - Traffic \& Transportation, 29(3), 311-319. https://doi.org/10.7307/ptt.v29i3.2195

[20] Virovac, D., Domitrovic, A., \& Bazijanac, E. (2017). The influence of human factor in aircraft maintenance. Promet Traffic \& Transportation, 29(3), 257-266. https://doi.org/10.7307/ptt.v29i3.2068

\section{Contact information}

\section{Milan KANKARAŠ, $\mathrm{PhD}$,}

Ministry of Defence of the Republic of Serbia,

Birčaninova 5, 11000 Belgrade, Serbia

E-mail: kankaras.milan@outlook.com

Nenad KAPOR, PhD, Professor,

(Corresponding author)

Megatrend Univerzity Fakultet of Civil Avioation, Serbia

Bulevar maršala Tolbuhina 8, 11000 Belgrade, Serbia

E-mail: nkapor@naisbitt.edu.rs

\section{Ivana CVETKOVIĆ, Mr,}

Ministry of Defence of the Republic of Serbia,

Birčaninova 5, 11000 Belgrade, Serbia

E-mail: ivana.cvetkovic@gmail.com

Dalibor PETROVIĆ, PhD,

Ministry of Defence of the Republic of Serbia,

Birčaninova 5, 11000 Belgrade, Serbia

E-mail: daliborpetrovic140@gmail.com 